\title{
Characterization of Silver Oxide Films Formed by Reactive RF Sputtering at Different Substrate Temperatures
}

\author{
P. Narayana Reddy, ${ }^{1}$ M. Hari Prasad Reddy, ${ }^{1}$ J. F. Pierson, ${ }^{2}$ and S. Uthanna ${ }^{1}$ \\ ${ }^{1}$ Department of Physics, Sri Venkateswara University, Tirupati-517 502, India \\ ${ }^{2}$ Department CP2S, Institut Jean Lamour (UMR CNRS 7198), University of Lorraine, 54011 Nancy Cedex, France \\ Correspondence should be addressed to P. Narayana Reddy; pnreddy66@gmail.com
}

Received 8 December 2013; Accepted 11 February 2014; Published 18 March 2014

Academic Editors: A. Baryshev and Y. S. Kivshar

Copyright (c) 2014 P. Narayana Reddy et al. This is an open access article distributed under the Creative Commons Attribution License, which permits unrestricted use, distribution, and reproduction in any medium, provided the original work is properly cited.

Silver oxide $\left(\mathrm{A}_{2} \mathrm{O}\right)$ films were deposited on glass and silicon substrates held at temperatures in the range $303-473 \mathrm{~K}$ by reactive RF magnetron sputtering of silver target. The films formed at room temperature were single phase $\mathrm{Ag}_{2} \mathrm{O}$ with polycrystalline in nature, while those deposited at $373 \mathrm{~K}$ were improved in the crystallinity. The films deposited at $423 \mathrm{~K}$ were mixed phase of $\mathrm{Ag}_{2} \mathrm{O}$ and $\mathrm{Ag}$. Atomic force micrographs of the films formed at room temperature were of spherical shape grains with size of $85 \mathrm{~nm}$, whereas those deposited at $473 \mathrm{~K}$ were with enhanced grain size of $215 \mathrm{~nm}$ with pyramidal shape. Electrical resistivity of the single phase films formed at room temperature was $5.2 \times 10^{-3} \Omega \mathrm{cm}$ and that of mixed phase was $4.2 \times 10^{-4} \Omega \mathrm{cm}$. Optical band gap of single phase films increased from 2.05 to $2.13 \mathrm{eV}$ with the increase of substrate temperature from 303 to $373 \mathrm{~K}$, while in mixed phase films it was $1.92 \mathrm{eV}$.

\section{Introduction}

Silver-oxygen system (Ag-O) was extensively attracted by researchers due to its novel applications in high density optical storage devices, gas sensors, photovoltaic cells, photo diodes, and antibacterial coatings [1-6]. This system exists in different defined compounds, namely, $\mathrm{Ag}_{2} \mathrm{O}, \mathrm{AgO}, \mathrm{Ag}_{3} \mathrm{O}_{4}$, $\mathrm{Ag}_{4} \mathrm{O}_{3}, \mathrm{Ag}_{2} \mathrm{O}_{3}$, and $\mathrm{Ag}_{4} \mathrm{O}_{4}$. Among these oxides, $\mathrm{Ag}_{2} \mathrm{O}$ is the most thermodynamically stable. The compound $\mathrm{Ag}_{2} \mathrm{O}$ possesses a simple cubic structure at room temperature [7]. $\mathrm{Ag}_{2} \mathrm{O}$ in thin film form is a p-type semiconductor with a band gap ranging from 1.2 to $3.4 \mathrm{eV}$ due to the deviation in the stoichiometry, structure and crystallinity, phases, and physical properties arising from the employed deposition technique [8]. Thermal decomposition of silver oxide into oxygen and silver is the unique characteristics which led to the promising technological applications. Kim et al. [9] reported that silver oxide films also act as a mask layer in magneto-optical disk to enhance the magneto-optical signal. However, the high threshold of thermal decomposition temperature $>673 \mathrm{~K}$ for silver oxide films has been a bottleneck of application in optical and magneto-optical storage $[10,11]$.
The $\mathrm{Ag}_{2} \mathrm{O}$ films grown with (111) orientation by rapid thermal annealing process at temperature of $473 \mathrm{~K}$ find application as readout layer in a magneto-optical disk. Peyser et al. [12] achieved strong photoactivated emission of nanoscale $\mathrm{Ag}_{2} \mathrm{O}$ for excitation with a wavelength $<520 \mathrm{~nm}$ find application in blue optical lasers. Nanoparticles of $\mathrm{Ag}_{2} \mathrm{O}$ embedded in $\mathrm{ZnO}$ inhibit the degradation in the performance of photodetector when annealed in oxygen ambient at temperature of $473 \mathrm{~K}$ [3]. Büchel et al. [13] effectively employed silver oxide as a substrate for the surface enhanced Raman spectroscopy for molecular level detection. Her et al. [14] incorporated silver oxide films into super resolution near field structures in optical memories.

Thin films of silver oxide can be prepared by various techniques such as thermal oxidation of silver films [5], thermal evaporation $[15,16]$, electron beam evaporation [17], pulsed laser deposition [18], chemical vapour deposition [19], electrodeposition [20], DC sputtering [8, 10, 21-25], and RF sputtering $[7,11,26,27]$. Among these deposition techniques, $\mathrm{RF}$ magnetron sputtering is one of the promising techniques for preparation of $\mathrm{Ag}_{2} \mathrm{O}$ films because of the advantages of high deposition rates, uniformity on large area 
TABLE 1: Sputter deposition parameters fixed for the growth of silver oxide films.

\begin{tabular}{lc}
\hline Deposition method & RF magnetron sputtering \\
Sputter target & Silver $(50 \mathrm{~mm}$ dia. and $3 \mathrm{~mm}$ thick $)$ \\
Target to substrate distance & $65 \mathrm{~mm}$ \\
Base pressure & $5 \times 10^{-4} \mathrm{~Pa}$ \\
Oxygen partial pressure & $2 \times 10^{-2} \mathrm{~Pa}$ \\
Sputter pressure & $4 \mathrm{~Pa}$ \\
Substrate temperature $\left(T_{s}\right)$ & $303-473 \mathrm{~K}$ \\
Sputter power & $65 \mathrm{~W}$ \\
\hline
\end{tabular}

substrates, precise control on the chemical composition and physical properties. In RF magnetron sputtering, the physical properties of the deposited thin films critically depend on the sputter parameters such as oxygen partial pressure, substrate temperature, and substrate bias voltage, sputtering pressure and sputter power. The influence of oxygen partial pressure on the structural, electrical, and optical properties of silver oxide films formed by RF magnetron sputtering was earlier reported [28]. In the present investigation, nanocrystalline $\mathrm{Ag}_{2} \mathrm{O}$ films were deposited on glass and silicon substrate by $\mathrm{RF}$ magnetron sputtering at different substrate temperatures. The effect of substrate temperature on the crystallographic structure and surface morphology, core level binding energies, and electrical and optical properties was systematically studied and the results were reported.

\section{Experimentation}

Thin films of silver oxide were deposited on glass and silicon substrates using RF magnetron sputtering method. Metallicsilver (99.9\% pure) of $50 \mathrm{~mm}$ diameter and $3 \mathrm{~mm}$ thickness was used as sputter target. The base pressure of $5 \times$ $10^{-4} \mathrm{~Pa}$ was achieved in the sputter chamber using diffusion pump and rotary pump combination. Argon was used as the sputter gas and oxygen as reactive gas. The required quantities of reactive gas of oxygen and sputter gas of argon were admitted into the sputter chamber through fine controlled needle valves. The distance between the target and substrate maintained was $65 \mathrm{~mm}$. The sputter target was powered with Advanced Energy RF power generator. The power fed to the sputter target was $65 \mathrm{~W}$. Films were deposited at oxygen partial pressure of $2 \times 10^{-2} \mathrm{~Pa}$ and sputter pressure of $4 \mathrm{~Pa}$ and at different substrate temperatures in the range 303$473 \mathrm{~K}$. The sputter deposition parameters maintained for preparation of silver oxide films are given in Table 1.

The deposited silver oxide films were characterized by studying their structural, morphological, electrical, and optical properties. The thickness of the deposited films determined with Veeco Dektak (model 150) depth profilometer was in the range $95-125 \mathrm{~nm}$. The crystallographic structure of the films was determined with X-ray diffraction (XRD) taken on a Bruker D8 Advanced diffractometer using monochromatic $\mathrm{Cu} \mathrm{K} \mathrm{K}_{\alpha 1}$ radiation with wavelength of $0.15406 \mathrm{~nm}$. The core level binding energies of the films was analyzed with Philips X-ray photoelectron spectrometer (Model PHI 300).

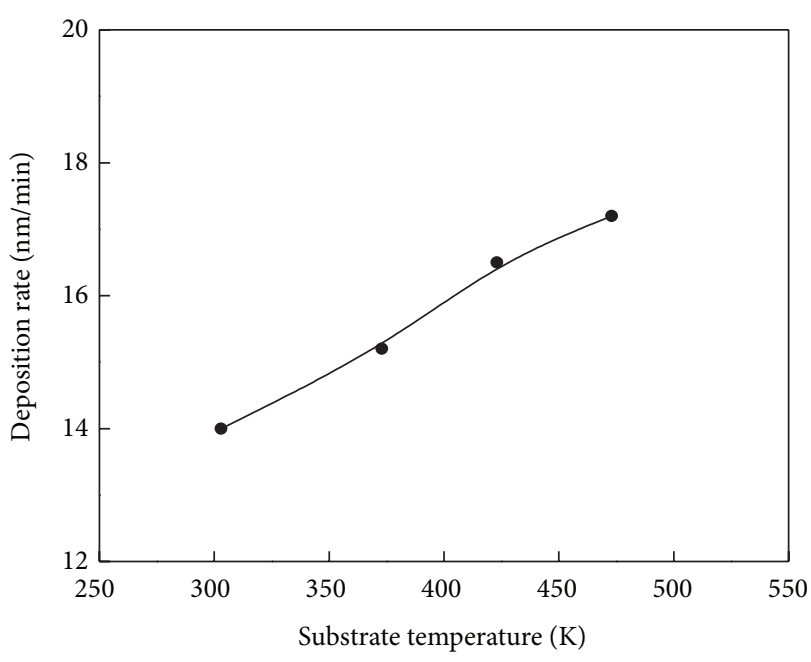

FIgURE 1: Variation in the deposition rate of $\mathrm{Ag}_{2} \mathrm{O}$ films with substrate temperature.

The surface morphology of the films was analyzed with atomic force microscope (Model SPA 400). The electrical resistivity of the films was measured at room temperature using four point probe (Jandel multiposition probe) technique. The optical transmittance of the films was recorded with Perkin-Elmer double beam spectrophotometer in the wavelength range $500-2500 \mathrm{~nm}$.

\section{Results and Discussion}

The deposition rate of the films was calculated from the thickness and the duration of deposition. The deposition rate of the films was highly influenced by the substrate temperature. The variation of deposition rate with the substrate temperature of the films was shown in Figure 1. The deposition rate of the films increased from 14 to $17.5 \mathrm{~nm} / \mathrm{min}$ with the increase of substrate temperature from 303 to $473 \mathrm{~K}$, respectively. It is to be noted that the formation of oxide phase during reactive sputtering occurs very nearto the substrate surface and the rate of reaction is increased with substrate temperature hence of higher deposition rate [26].

Figure 2 shows the $\mathrm{X}$-ray diffraction profiles of the silver oxide films deposited on glass substrates held at temperatures in the range $303-473 \mathrm{~K}$. The films formed at room temperature $(303 \mathrm{~K})$ showed a strong X-ray diffraction peak at $2 \theta=32.7^{\circ}$ and two weak peaks at $54.7^{\circ}$ and $68.7^{\circ}$ (shown in inset of Figure 2). These diffraction (111), (220), and (222) reflections are related to the cubic structure of $\mathrm{Ag}_{2} \mathrm{O}$ (ICCD Card number: 00-41-1104). It indicates that the grown films were of polycrystalline in nature. The films formed at substrate temperature of $373 \mathrm{~K}$ showed that the enhancement in the intensity of (111) reflection indicated the increase in the crystallinity of the $\mathrm{Ag}_{2} \mathrm{O}$ films. As the substrate temperature increased to $423 \mathrm{~K}$ the intensity of the (111) reflection of $\mathrm{Ag}_{2} \mathrm{O}$ decreased with the presence of additional three diffraction peaks at $38.0^{\circ}, 44.1^{\circ}$, and $54.8^{\circ}$. The diffraction peak situated at $38.0^{\circ}$ is related to the (200) reflection of $\mathrm{Ag}_{2} \mathrm{O} /(111)$ of $\mathrm{Ag}$, and the peaks at $44.1^{\circ}$ and $54.8^{\circ}$ correspond to the (200) and 

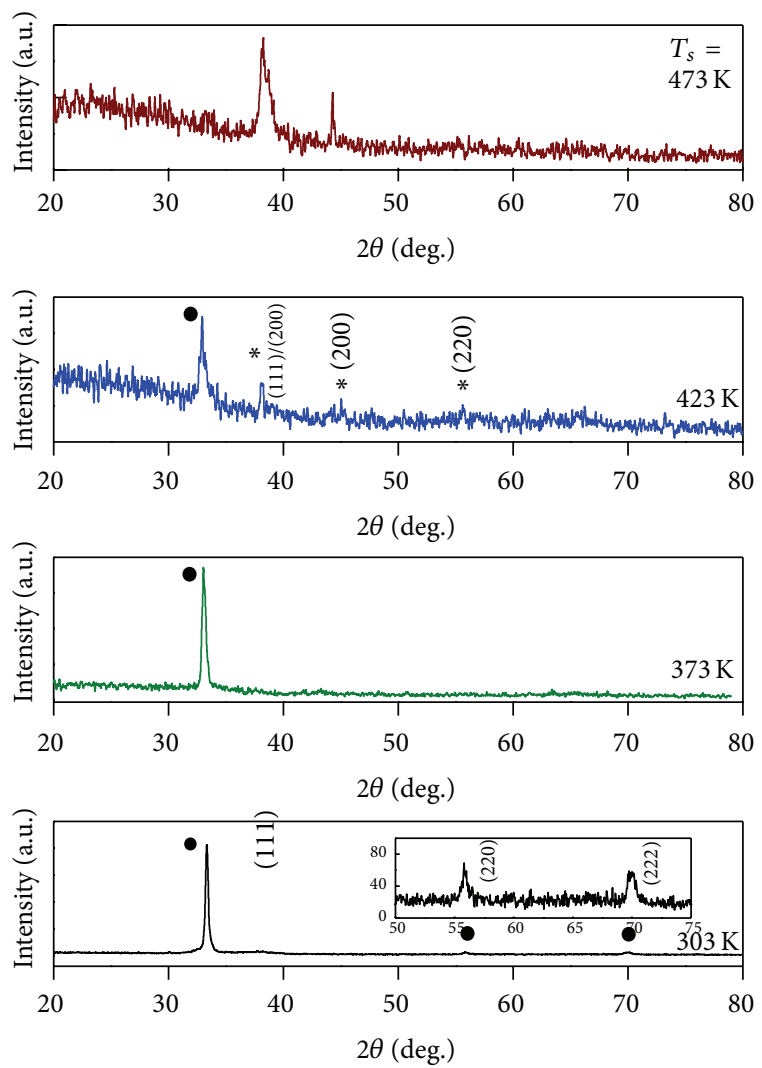

- $\mathrm{Ag}_{2} \mathrm{O}$

* Ag

FIGURE 2: XRD profiles of $\mathrm{Ag}_{2} \mathrm{O}$ films formed at different substrate temperatures.

(220) reflections of metallic silver (ICCD Card number: 00004-0783). It revealed that the films formed at $423 \mathrm{~K}$ were of mixed phase of $\mathrm{Ag}_{2} \mathrm{O}$ and $\mathrm{Ag}$. The films are deposited at higher substrate temperature of $473 \mathrm{~K}$, the (111) reflection of $\mathrm{Ag}_{2} \mathrm{O}$ disappeared, and increase in the intensity of the peak at $38.0^{\circ}$ increased. Based on the intensities of the diffraction peak, at higher substrate temperature of $473 \mathrm{~K}$, the films were transformed from $\mathrm{Ag}_{2} \mathrm{O}$ phase to metallic silver. The decomposition of $\mathrm{Ag}_{2} \mathrm{O}$ to silver was also noticed by Gao et al. [21] in DC magnetron sputtered $\mathrm{Ag}_{2} \mathrm{O}$ films. It was also reported that the $\mathrm{Ag}_{2} \mathrm{O}$ decomposed into $\mathrm{Ag}$ after the heat treatment in the temperature range 473-673 K [29]. Pierson and Rousselot [7] noticed that the single phase $\mathrm{Ag}_{2} \mathrm{O}$ films formed by RF sputtering with oxygen flow rate of $9 \mathrm{sccm}$ were decomposed into silver by heat treatment at $473 \mathrm{~K}$, while the mixed phase $\left(\mathrm{Ag}_{2} \mathrm{O}+\mathrm{Ag}\right)$ films formed with $6 \mathrm{sccm}$ of oxygen flow rate were transformed into silver at temperature of $673 \mathrm{~K}$.

The crystallite size $(L)$ of the films was evaluated from the full width at half maximum intensity of X-ray diffraction peaks using Debye- Scherrer's relation

$$
L=\frac{k \lambda}{\beta \cos \theta},
$$

where $k$ is a constant with a value of 0.89 for copper X-ray radiation and $\beta$ the full width at half maximum intensity

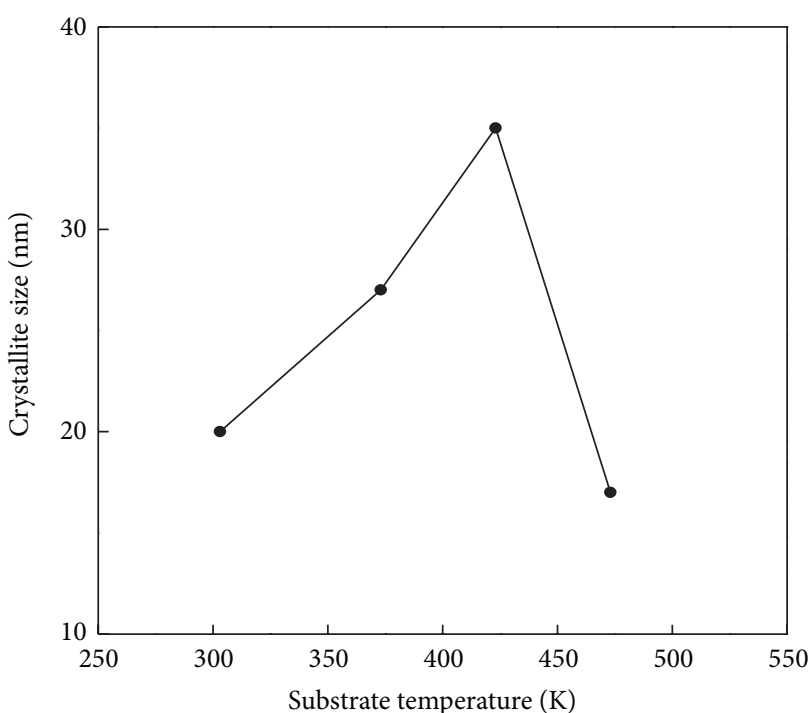

Figure 3: Dependence of crystallite size of $\mathrm{Ag}_{2} \mathrm{O}$ films on the substrate temperature.

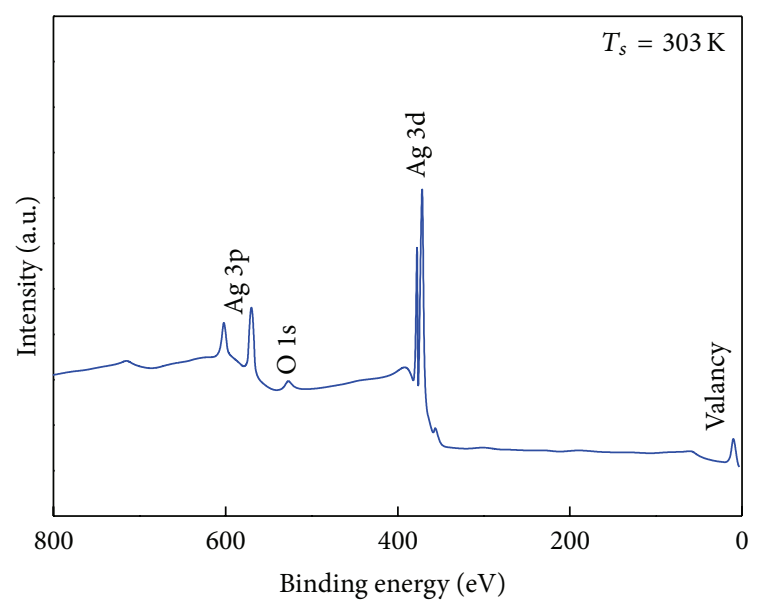

FIGURE 4: XPS survey scan of silver oxide films formed at substrate temperature of $303 \mathrm{~K}$ and $473 \mathrm{~K}$.

of diffraction peak measured in radians. The crystallite size increased from 20 to $35 \mathrm{~nm}$ (Figure 3) with increase of substrate temperature from 303 to $373 \mathrm{~K}$ due to improvement in crystallinity of the films. The mixed phase films formed at $423 \mathrm{~K}$ showed the crystalline size of $14 \mathrm{~nm}$ and at higher substrate temperature of 473 it decreased to $10 \mathrm{~nm}$ as shown in Figure 3. The sharp decrease in the crystallite size at substrate temperature of $473 \mathrm{~K}$ was due to decomposition of $\mathrm{Ag}_{2} \mathrm{O}$ into Ag.

The X-ray photoelectron spectroscopic studies were performed on the films formed on silicon substrates held at different temperatures in order to determine the core level binding energies present in the films. Figure 4 shows a representative survey X-ray photoelectron spectrum of silver oxide films formed at $303 \mathrm{~K}$. The spectrum showed the characteristic core level binding energies at about 368 and $374 \mathrm{eV}$ related to the $\mathrm{Ag} 3 \mathrm{~d}_{5 / 2}$ and $\mathrm{Ag} 3 \mathrm{~d}_{3 / 2}$, respectively, due 


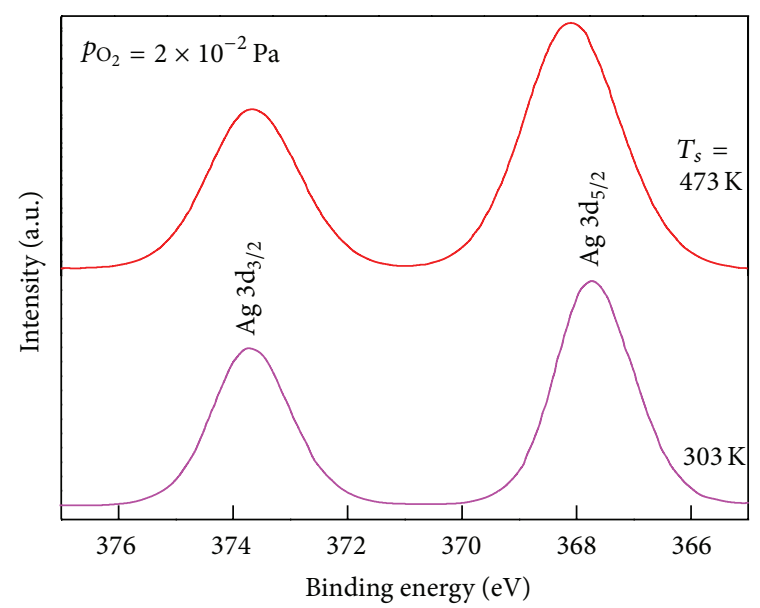

(a)

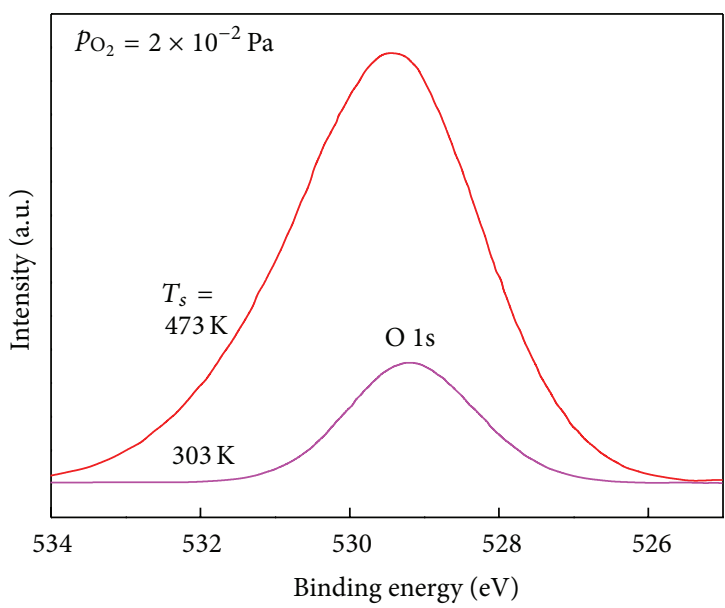

(b)

FIGURE 5: XPS narrow scan spectra of silver oxide films formed at substrate temperature of $303 \mathrm{~K}$ and $473 \mathrm{~K}$ : (a) Ag $3 \mathrm{~d}$ and (b) O 1s.

the spin-orbit splitting of energy levels, and peaks situated at $573 \mathrm{eV}$ and $604 \mathrm{eV}$ correspond to the core levels of $\mathrm{Ag}$ $3 \mathrm{p}_{3 / 2}$ and $\mathrm{Ag} 3 \mathrm{p}_{1 / 2}$, respectively, related to the $\mathrm{Ag}_{2} \mathrm{O}$ films [30]. Figures 5(a) and 5(b) show the narrow scan spectra of $\mathrm{Ag} 3 \mathrm{~d}$ and $\mathrm{O}$ 1s of silver oxide films formed at $303 \mathrm{~K}$ and $473 \mathrm{~K}$. The films formed at $303 \mathrm{~K}$ showed core level binding energies of $\mathrm{Ag} 3 \mathrm{~d}_{5 / 2}$ at $367.7 \mathrm{eV}$ and $\mathrm{O}$ 1s at $529.2 \mathrm{eV}$. In the case of the films formed at substrate temperature of $473 \mathrm{~K}$, the core level binding energy of $\mathrm{Ag} 3 \mathrm{~d}_{5 / 2}$ was shifted to $367.3 \mathrm{eV}$ and $\mathrm{O}$ 1s shifted to $530.2 \mathrm{eV}$. The achieved core level binding energies in the $\mathrm{Ag}_{2} \mathrm{O}$ films formed at $303 \mathrm{~K}$ were in agreement with the reports of Abe et al. [31] in reactive $\mathrm{RF}$ sputtered films. It is to be noted that $\mathrm{Ag}_{2} \mathrm{O}$ core level binding energy was in the range $367.6-367.8 \mathrm{eV}$ and $\mathrm{O} 1 \mathrm{~s}$ was in the range $529.2-529.5 \mathrm{eV}$, while in pure metallic silver the Ag $3 d_{5 / 2}$ was in the range $368.0-368.3 \mathrm{eV}[10,31,32]$. From these studies it is revealed that the films formed at $303 \mathrm{~K}$ were of single phase $\mathrm{Ag}_{2} \mathrm{O}$, while those deposited at $473 \mathrm{~K}$ were of mixed phase of $\mathrm{Ag}_{2} \mathrm{O}$ and metallic silver. It was also confirmed by X-ray diffraction studies. It indicated that the films formed at substrate temperature of $303 \mathrm{~K}$ and $373 \mathrm{~K}$ were of $\mathrm{Ag}_{2} \mathrm{O}$, mixed phase of $\mathrm{Ag}_{2} \mathrm{O}$ and $\mathrm{Ag}$, at $423 \mathrm{~K}$ and at higher temperature of $473 \mathrm{~K}$ the grown films were of metallic silver.

Figure 6 shows three-dimensional and two-dimensional atomic force micrographs of films formed at different substrate temperatures. The micrographs showed different morphology of the grain growth depending on the substrate temperature. Atomic force micrographs of the films formed at $303 \mathrm{~K}$ showed spherical shape grains with size of $85 \mathrm{~nm}$. When substrate temperature increased to $473 \mathrm{~K}$ the size of the grains increased to $215 \mathrm{~nm}$ and also transformed from the spherical shape grains into pyramidal-like shape. The films formed at substrate temperatures $303 \mathrm{~K}$ were uniform with root mean square roughness of $4.5 \mathrm{~nm}$. The root mean square roughness of the films increased from 8.0 to $10.9 \mathrm{~nm}$ with increase of substrate temperature from $423 \mathrm{~K}$ to $473 \mathrm{~K}$, respectively. The increase of surface roughness of the films with the substrate temperature may be due to the decomposition of $\mathrm{Ag}_{2} \mathrm{O}$ phase into silver and oxygen.

The electrical resistivity of the deposited thin films is very sensitive to the grown phase and its microstructure. The substrate temperature has high influence on the electrical properties of the deposited films. The dependence of electrical resistivity of the films on the substrate temperature is shown in Figure 7. The single phase $\mathrm{Ag}_{2} \mathrm{O}$ films formed at room temperature exhibited the electrical resistivity of 5.2 $\times 10^{-3} \Omega \mathrm{cm}$. The electrical resistivity of the films formed at substrate temperature of 373 was $3.0 \times 10^{-3} \Omega \mathrm{cm}$. The decrease of electrical resistivity with increase of substrate temperature up to $373 \mathrm{~K}$ was due to the improvement in the crystallinity of the films. The films formed at $423 \mathrm{~K}$ exhibited the electrical resistivity of $1.8 \times 10^{-3} \Omega \mathrm{cm}$. The low electrical resistivity of the films formed at $423 \mathrm{~K}$ was may be due to the presence of mixed phase of $\mathrm{Ag}_{2} \mathrm{O}$ and $\mathrm{Ag}$. Further increase of substrate temperature to $473 \mathrm{~K}$; resistivity of the films decreased to $4.2 \times 10^{-4} \Omega \mathrm{cm}$ because of transformation into metallic silver. The phase transformation from $\mathrm{Ag}_{2} \mathrm{O}$ to $\mathrm{Ag}$ was also confirmed by the $\mathrm{X}$-ray diffraction. Varkey and Fort [19] reported that the $\mathrm{Ag}_{2} \mathrm{O}$ and $\mathrm{AgO}$ films formed on glass substrates by chemical bath deposition showed the electrical resistivity of $0.5 \Omega \mathrm{cm}$ and $0.12 \Omega \mathrm{cm}$, respectively. Ravi Chandra Raju et al. [18] reported that the electrical resistivity increased from $1 \times 10^{-2}$ to $4 \times 10^{2} \Omega \mathrm{cm}$ with the increase of oxygen partial pressure from 9 to $50 \mathrm{~Pa}$ in pulsed laser deposited silver oxide films. The reported electrical resistivity in the $\mathrm{Ag}_{2} \mathrm{O}$ films varied depending on the deposition method employed and the process conditions maintained during the growth of the films.

Figure 8 shows the wavelength dependent optical transmittance of the films formed at different substrate temperatures. The optical transmittance of the films formed at $303 \mathrm{~K}$ was about $24 \%$ (at wavelength of $1000 \mathrm{~nm}$ ). The optical transmittance of the films increased to $58 \%$ with increase of substrate temperature up to $373 \mathrm{~K}$. With further increase 


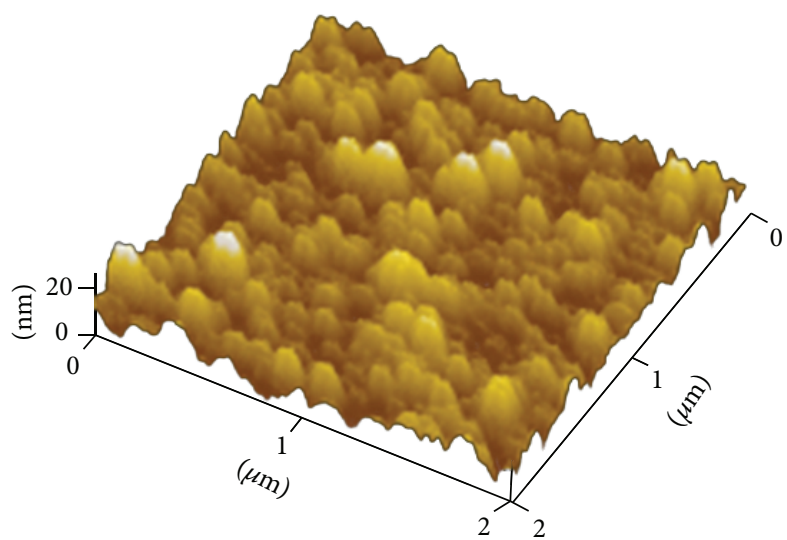

(a)

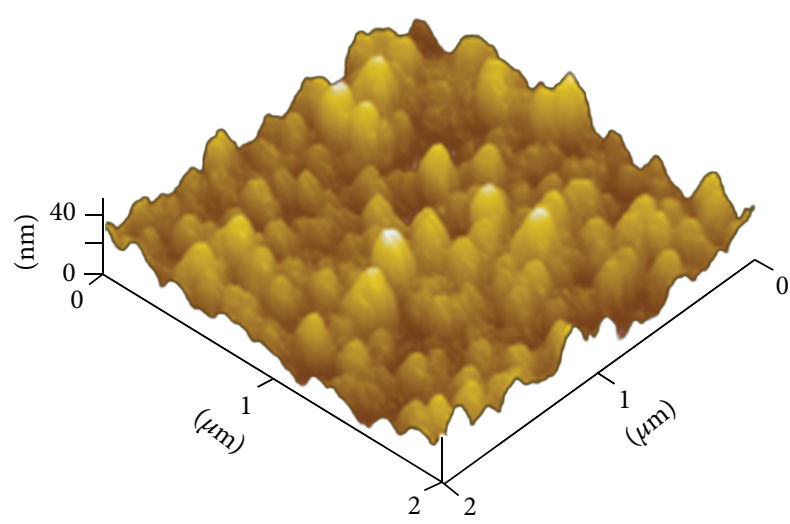

(b)

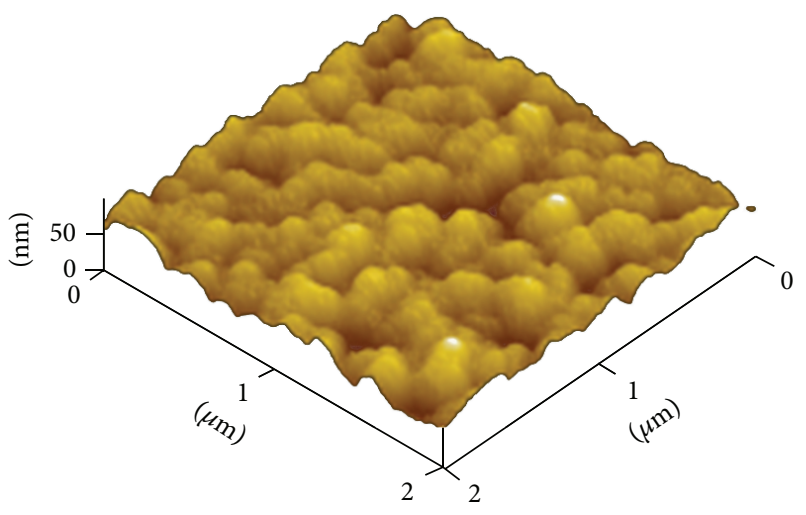

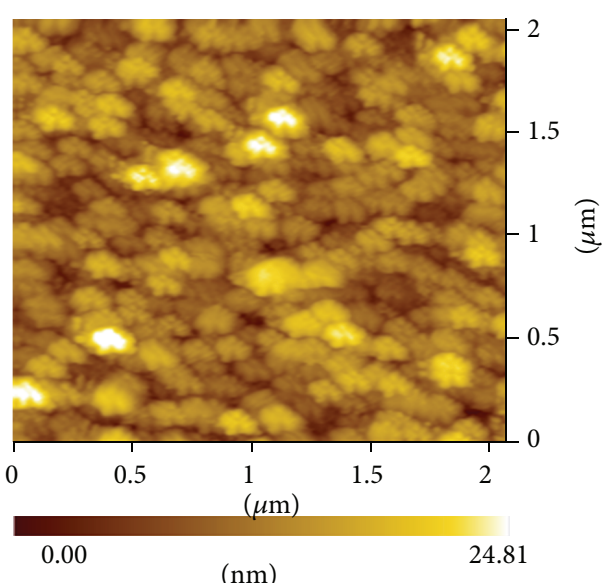
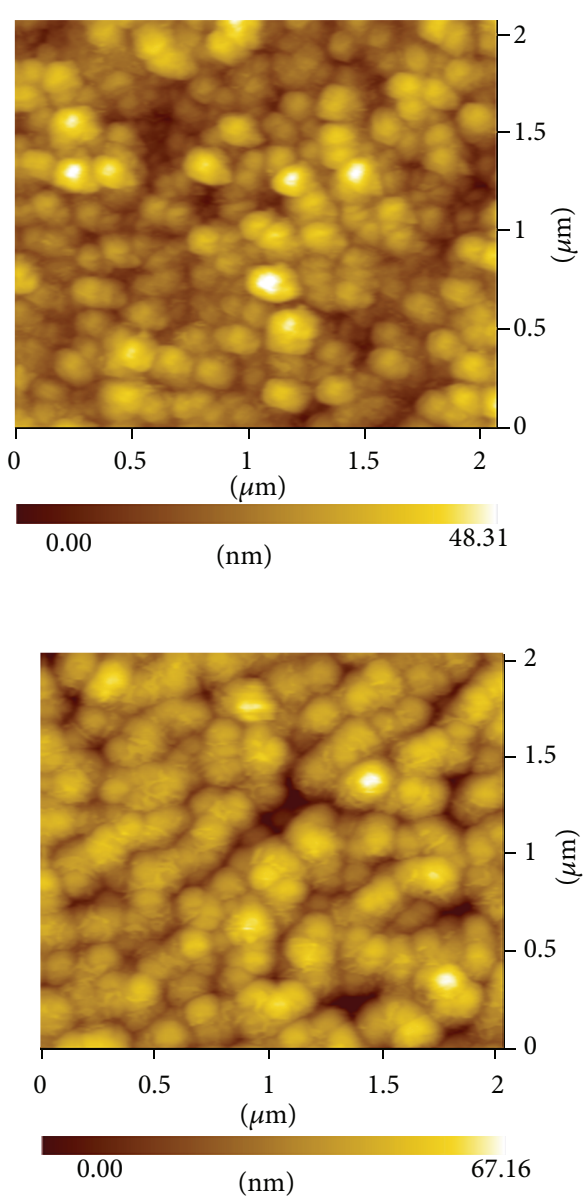

(c)

Figure 6: AFM 3d- and 2d-micrographs of $\mathrm{Ag}_{2} \mathrm{O}$ films formed at substrate temperatures: (a) $303 \mathrm{~K}$, (b) $423 \mathrm{~K}$, and (c) $473 \mathrm{~K}$.

of substrate temperature to $423 \mathrm{~K}$ the transmittance of the films decreased to $46 \%$. The decrease in the transmittance in the films formed at $423 \mathrm{~K}$ was due to the mixed phase of $\mathrm{Ag}_{2} \mathrm{O}$ and $\mathrm{Ag}$ where the metallic silver scatters the photons hence decreased in the transmittance. The films formed at higher substrate temperature of 473 ; there was decrease in the transmittance to $28 \%$. The optical absorption edge of the films was shifted towards lower wavelength side with increase of substrate temperature from 303 to $373 \mathrm{~K}$. With further increase of substrate temperature the absorption edge shifted towards higher wavelength side as shown in Figure 8. The absorption coefficient $(\alpha)$ of the films was calculated from the optical transmittance $(T)$ data using the relation

$$
\alpha=-\left(\frac{1}{t}\right) \ln \left(\frac{1}{T}\right),
$$




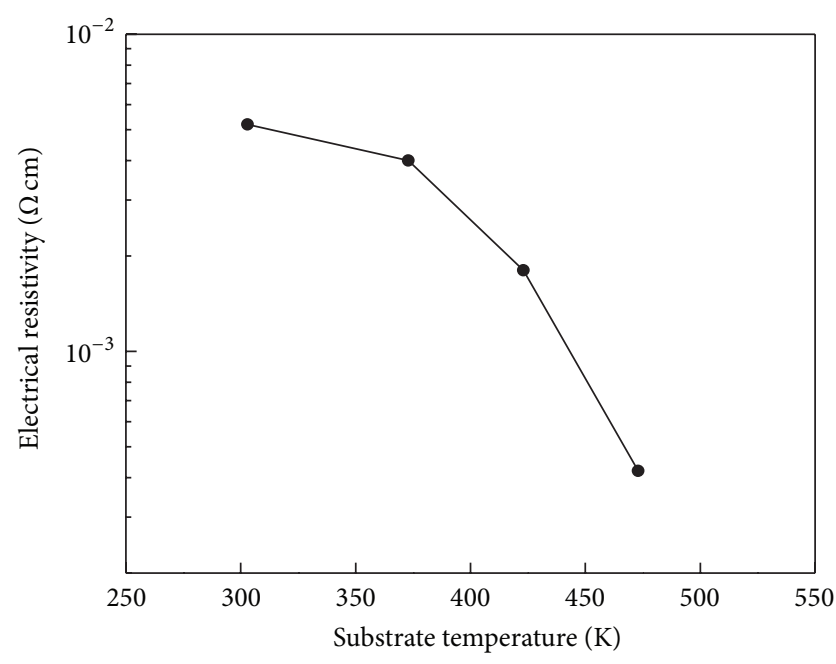

FIGURE 7: Dependence of electrical resistivity of $\mathrm{Ag}_{2} \mathrm{O}$ films on the substrate temperature.

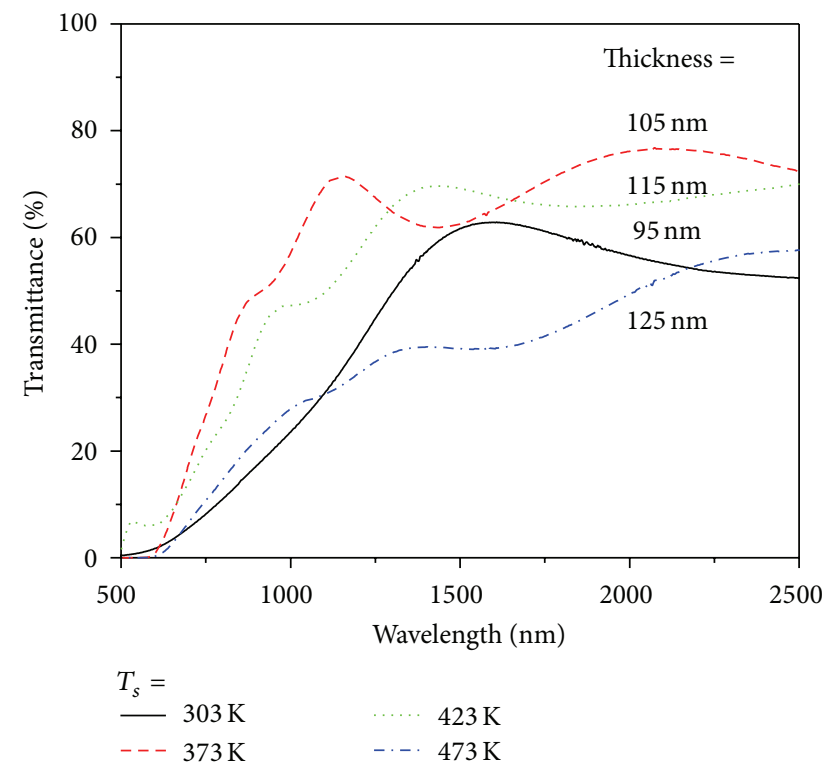

Figure 8: Optical transmittance spectra of $\mathrm{Ag}_{2} \mathrm{O}$ films formed at different substrate temperatures.

where $t$ is the film thickness. The optical band gap $\left(E_{g}\right)$ of the films was estimated from the plots of $(\alpha h \nu)^{2}$ versus photon energy $(h v)$ using Tauc's relation [33]:

$$
(\alpha h \nu)=A\left(h \nu-E_{g}\right)^{1 / 2},
$$

where $A$ is the absorption edge width parameter. Extrapolation of the linear portion of the plots of $(\alpha h \nu)^{2}$ versus photon energy to $\alpha=0$ resulted in the optical band gap of the films. The optical band gap of the films increased from 2.05 to $2.13 \mathrm{eV}$ with the increase of substrate temperature from 303 to $373 \mathrm{~K}$. Further it decreased to $1.92 \mathrm{eV}$ at substrate temperature of $423 \mathrm{~K}$. Varkey and Fort [19] reported an optical band gap of $2.25 \mathrm{eV}$ in $\mathrm{Ag}_{2} \mathrm{O}$ films produced by chemical bath deposition.
Pierson et al. [26] achieved an optical band gap of $2.23 \mathrm{eV}$ in $\mathrm{Ag}_{2} \mathrm{O}$ films formed by $\mathrm{DC}$ reactive magnetron sputtering. Rivers et al. [34] achieved a high optical band gap of $3.3 \mathrm{eV}$ in $\mathrm{Ag}_{2} \mathrm{O}$ films formed by evaporation of silver in the presence of ECR oxygen plasma. Ma et al. [27] reported an optical band gap decrease from 3.25 to $2.77 \mathrm{eV}$ with increase of substrate temperature from 373 to $498 \mathrm{~K}$ in $\mathrm{RF}$ reactive magnetron sputtered $\mathrm{Ag}_{2} \mathrm{O}$ films. The variations on the optical band gap for $\mathrm{Ag}_{2} \mathrm{O}$ films depend on the deposition method employed and the process parameters maintained during the growth of the films.

\section{Conclusions}

Silver oxide films were deposited on glass substrates by RF magnetron sputtering of pure silver target under various substrate temperatures in the range $303-473 \mathrm{~K}$. The effect of substrate temperature on the core level binding energies, structure and surface morphology, and electrical and optical properties was investigated. The films deposited at $303 \mathrm{~K}$ were polycrystalline with cubic structure of $\mathrm{Ag}_{2} \mathrm{O}$. As the substrate temperature increased to $373 \mathrm{~K}$, the crystallinity of the films increased. The films formed at substrate temperature of $423 \mathrm{~K}$ were of mixed phase of $\mathrm{Ag}_{2} \mathrm{O}$ and $\mathrm{Ag}$, while those deposited at $473 \mathrm{~K}$ were of single phase $\mathrm{Ag}$. The phase transformation from $\mathrm{Ag}_{2} \mathrm{O}$ to Agwas also confirmed from the core level binding energies determined by X-ray photoelectron spectroscope. Atomic force microscopic studies on the films indicated that the grain growth transformed from spherical to pyramidallike shape with increase of substrate temperature from 303 to $473 \mathrm{~K}$, respectively. Single phase $\mathrm{Ag}_{2} \mathrm{O}$ films formed at $303 \mathrm{~K}$ exhibited the electrical resistivity of $5.2 \times 10^{-3} \Omega \mathrm{cm}$, while those deposited at $473 \mathrm{~K}$ decreased to $4.29 \times 10^{-4} \Omega \mathrm{cm}$ due to the formation of metallic silver. The optical band gap of the $\mathrm{Ag}_{2} \mathrm{O}$ films increased from 2.05 to $2.13 \mathrm{eV}$ with increase of substrate temperature from 303 to $373 \mathrm{~K}$ due to improvement in the crystallinity, while in the case of mixed phase of $\mathrm{Ag}_{2} \mathrm{O}$ and $\mathrm{Ag}$ films deposited at substrate temperature of $423 \mathrm{~K}$ the optical band gap of $1.92 \mathrm{eV}$ was shown.

\section{Conflict of Interests}

The authors declare that there is no conflict of interests regarding the publication of this paper.

\section{References}

[1] A. Kiazadeh, H. L. Gomes, A. M. Rosa da Costa, J. A. Moreira, M. de Leuw, and S. C. J. Meskers, "Intrinsic and extrinsic resistive switching in a planar diode based on silver oxide nanoparticles," Thin Solid Films, vol. 522, pp. 407-411, 2012.

[2] D. Dellasega, C. S. Casari, F. Vario, C. Conti, C. E. Bottani, and A. L. Bassi, "Nanostructured $\mathrm{Ag}_{4} \mathrm{O}_{4}$ thin films produced by ion beam oxidation of silver," Applied Surface Science, vol. 266, pp. 161-169, 2013.

[3] Z. S. Hu, F. Y. Hung, K. J. Chen et al., "Recovery of thermal degraded $\mathrm{ZnO}$ photodetector by embedding nanosilver oxide nanoparticles," Applied Surface Science, vol. 279, pp. 31-35, 2013. 
[4] H. Fuji, J. Tominaga, L. Men, T. Nakano, H. Katayama, and N. Atoda, "A near-field recording and readout technology using a metallic probe in an optical disk," Japanese Journal of Applied Physics, Part 1: Regular Papers and Short Notes and Review Papers, vol. 39, pp. 980-981, 2000.

[5] M. A. Muhsien and H. H. Hamdan, "Preparation and characterization of $\mathrm{p}-\mathrm{Ag}_{2} \mathrm{O} / \mathrm{n}-\mathrm{Si}$ heterojunction devices produced by rapid thermal oxidation," Energy Proceedia, vol. 18, pp. 300-311, 2012.

[6] E. Tselepis and E. Fortin, "Preparation and photovoltaic properties of anodically grown $\mathrm{Ag}_{2} \mathrm{O}$ films," Journal of Materials Science, vol. 21, no. 3, pp. 985-988, 1986.

[7] J. Pierson and C. Rousselot, "Stability of reactively sputtered silver oxide films," Surface and Coatings Technology, vol. 200, no. 1-4, pp. 276-279, 2005.

[8] X. Gao, H. Feng, J. Ma et al., "Analysis of the dielectric constants of the $\mathrm{Ag}_{2} \mathrm{O}$ film by spectroscopic ellipsometry and singleoscillator model," Physica B: Condensed Matter, vol. 405, no. 7, pp. 1922-1926, 2010.

[9] J. Kim, H. Fuji, Y. Yamakawa et al., "Magneto-optical characteristics enhanced by super resolution near field structure," Japanese Journal of Applied Physics, Part 2: Letters, vol. 40, pp. 1634-1636, 2001.

[10] X. Gao, S. Wang, J. Li et al., "Study of structure and optical properties of silver oxide films by ellipsometry, XRD and XPS methods," Thin Solid Films, vol. 455-456, pp. 438-442, 2004.

[11] Y. Chiu, U. Rambabu, M. Hsu, H. D. Shieh, C. Chen, and H. Lin, "Fabrication and nonlinear optical properties of nanoparticle silver oxide films," Journal of Applied Physics, vol. 94, no. 3, pp. 1996-2001, 2003.

[12] L. A. Peyser, A. E. Vinson, A. P. Bartko, and R. M. Dickson, "Photoactivated fluorescence from individual silver nanoclusters," Science, vol. 291, no. 5501, pp. 103-106, 2001.

[13] D. Büchel, C. Mihalcea, T. Fukaya et al., "Sputtered silver oxide layers for surface-enhanced Raman spectroscopy," Applied Physics Letters, vol. 79, no. 5, pp. 620-622, 2001.

[14] Y. Her, Y. Lan, W. Hsu, and S. Tsai, "Effect of constituent phases of reactively sputtered $\mathrm{AgO}_{x}$ film on recording and readout mechanisms of super-resolution near-field structure disk," Journal of Applied Physics, vol. 96, no. 3, pp. 1283-1288, 2004.

[15] M. F. Al-Kuhaili, "Characterization of thin films produced by the thermal evaporation of silver oxide," Journal of Physics D: Applied Physics, vol. 40, no. 9, pp. 2847-2853, 2007.

[16] S. M. Hou, M. Ouyang, H. F. Chen et al., "Fractal structure in the silver oxide thin film," Thin Solid Films, vol. 315, no. 1-2, pp. 322-326, 1998.

[17] L. A. A. Pettersson and P. G. Snyder, "Preparation and characterization of oxidized silver thin films," Thin Solid Films, vol. 270, no. 1-2, pp. 69-72, 1995.

[18] N. Ravi Chandra Raju, K. Jagadeesh Kumar, and A. Subrahmanyam, "Physical properties of silver oxide thin films by pulsed laser deposition: effect of oxygen pressure during growth," Journal of Physics D: Applied Physics, vol. 42, no. 13, Article ID 135411, 6 pages, 2009.

[19] A. J. Varkey and A. F. Fort, "Some optical properties of silver peroxide $(\mathrm{AgO})$ and silver oxide $\left(\mathrm{Ag}_{2} \mathrm{O}\right)$ films produced by chemical-bath deposition," Solar Energy Materials and Solar Cells, vol. 29, no. 3, pp. 253-259, 1993.

[20] Y. Yuan, R. Yuan, Y. Chai, Y. Zhuo, L. Mao, and S. Yuan, "A novel label-free electrochemical immunosensor for carcinoembryonic antigen detection based on the $\left[\mathrm{Ag}-\mathrm{Ag}_{2} \mathrm{O}\right] / \mathrm{SiO}_{2}$ nanocomposite material as a redox probe," Journal of Electroanalytical Chemistry, vol. 643, no. 1-2, pp. 15-19, 2010.

[21] X. Gao, H. Feng, Z. Zhang, J. Ma, and J. Lu, "Effects of rapid thermal processing on microstructure and optical properties of as-deposited $\mathrm{Ag}_{2} \mathrm{O}$ films by direct-current reactive magnetron sputtering," Chinese Physics Letters, vol. 27, no. 2, Article ID 026804, 2010.

[22] X. Gao, Z. Zhang, J. Ma, J. Lu, J. Gu, and S. Yang, "Effects of the sputtering power on the crystalline structure and optical properties of the silver oxide films deposited using directcurrent reactive magnetron sputtering," Chinese Physics $B$, vol. 20, no. 2, Article ID 026103, 6 pages, 2011.

[23] H. L. Feng, X. Y. Gao, Z. Y. Zhang, and J. M. Ma, "Study on the crystalline structure and the thermal stability of silver-oxide films deposited by using direct-current reactive magnetron sputtering methods," Journal of the Korean Physical Society, vol. 56, no. 4, pp. 1176-1179, 2010.

[24] H. E. Mehdi, M. R. Hantehzadeh, and S. Valedbagi, "Physical properties of silver oxide thin film prepared by DC magnetron sputtering: effect of oxygen partial pressure during growth," Journal of Fusion Energy, vol. 32, pp. 28-33, 2013.

[25] K. M. Zhao, Y. Liang, X. Y. Gao, C. Chen, X. M. Chen, and X. W. Zhao, "Evolution of the structural and optical properties of silver oxide films with different stoichiometries deposited by DC magnetron reactive sputtering," Chinese Physics B, vol. 21, Article ID 066101, 2012.

[26] J. F. Pierson, D. Wiederkehr, and A. Billard, "Reactive magnetron sputtering of copper, silver, and gold," Thin Solid Films, vol. 478, no. 1-2, pp. 196-205, 2005.

[27] J. Ma, Y. Liang, X. Gao et al., "Effect of substrate temperature on microstructure and optical properties of single-phased $\mathrm{Ag}_{2} \mathrm{O}$ film deposited by using radio-frequency reactive magnetron sputtering method," Chinese Physics B, vol. 20, no. 5, Article ID 056102, 5 pages, 2011.

[28] P. Narayana Reddy, A. Sreedhar, M. Hari Prasad Reddy, S. Uthanna, and J. F. Pierson, "The effect of oxygen partial pressure on physical properties of nano-crystalline silver oxide thin films deposited by RF magnetron sputtering," Crystal Research and Technology, vol. 46, no. 9, pp. 961-966, 2011.

[29] D. R. Lide, Ed., Handbook of Chemistry and Physics, pp. 4-83, CRC Press, Boca Raton, Fla, USA, 8th edition, 2003.

[30] L. H. Tjeng and M. B. J. Meinders, "Electronic structure of $\mathrm{Ag}_{2}$ O," Physical Review B, vol. 41, pp. 3190-3194, 1990.

[31] Y. Abe, T. Hasegawa, M. Kawamura, and K. Sasaki, "Characterization of $\mathrm{Ag}$ oxide thin films prepared by reactive $\mathrm{RF}$ sputtering," Vacuum, vol. 76, no. 1, pp. 1-6, 2004.

[32] D. Briggs and M. T. Seah, Practical Surface Analysis, Volume 1, John Wiley \& Sons, New York, NY, USA, 2nd edition, 1990.

[33] J. Tauc, Amorphous and Liquid Semiconductors, Plenum Press, New York, NY, USA, 1974.

[34] S. B. Rivers, G. Bernhardt, M. W. Wright, D. J. Frankel, M. M. Steeves, and R. J. Lad, "Structure, conductivity, and optical absorption of $\mathrm{Ag}_{2-x} \mathrm{O}$ films," Thin Solid Films, vol. 515, no. 24, pp. 8684-8688, 2007. 

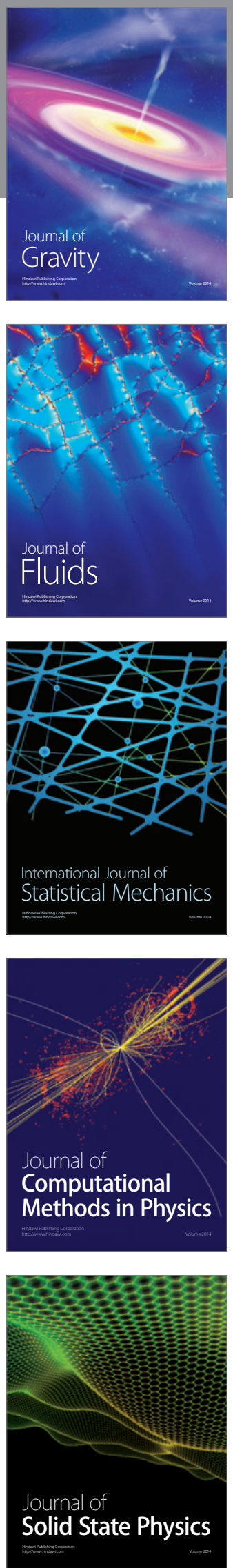

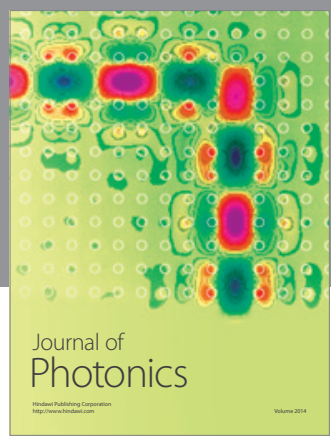

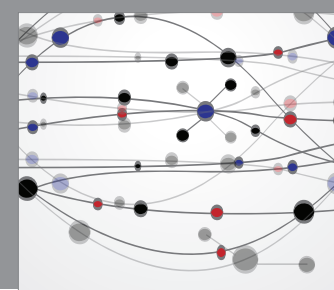

The Scientific World Journal

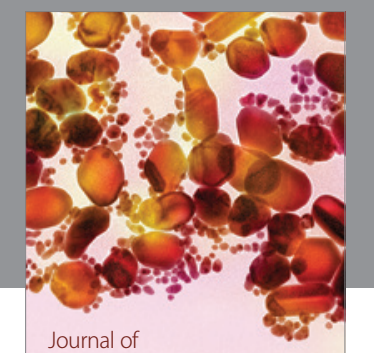

Soft Matter
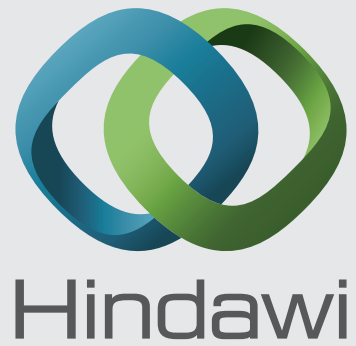

Submit your manuscripts at

http://www.hindawi.com
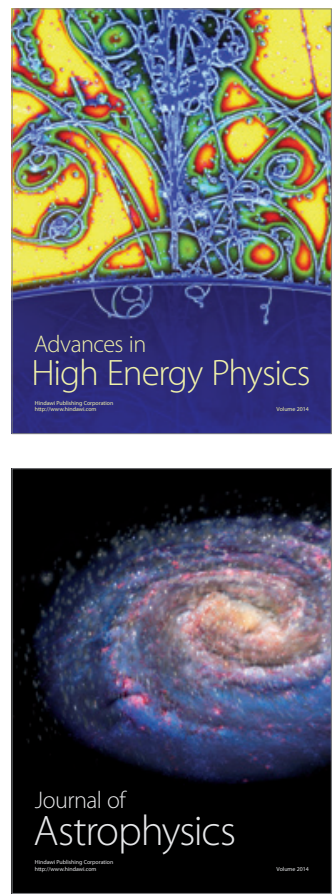
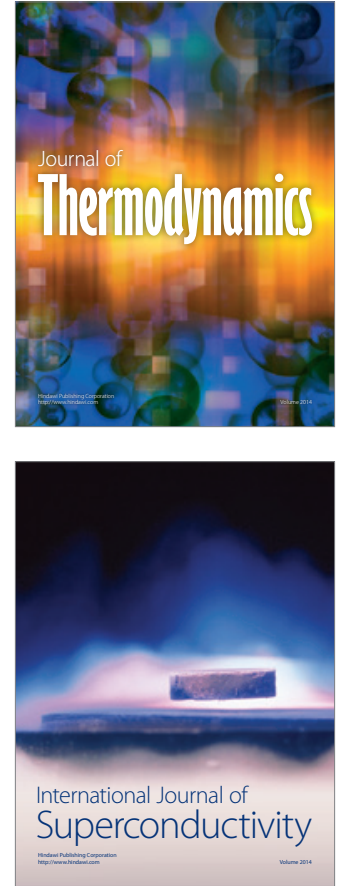
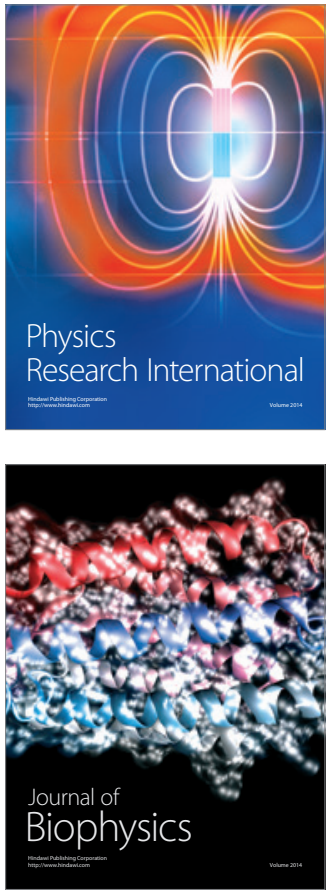
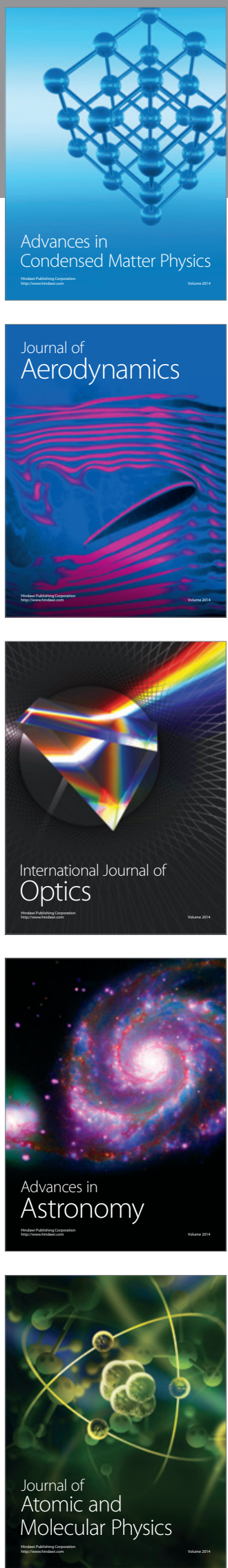